\title{
Coronectomy of Deeply Impacted Lower Third Molar: Incidence of Outcomes and Complications after One Year Follow-Up
}

\author{
Jimoh Olubanwo Agbaje ${ }^{1,2}$, Guido Heijsters ${ }^{2}$, Ahmed Sobhy Salem ${ }^{1,3}$, Sarah Van Slycke , \\ Serge Schepers ${ }^{2,4}$, Constantinus Politis ${ }^{1,5}$, Luc Vrielinck ${ }^{2}$ \\ ${ }^{1}$ OMFS-IMPATH Research Group, Department of Imaging and Pathology, Faculty of Medicine, Catholic University Leuven, \\ Leuven, Belgium. \\ ${ }^{2}$ Department of Oral and Maxillofacial Surgery, St. John's Hospital, Genk, Belgium. \\ ${ }^{3}$ Department of Oral and Maxillofacial Surgery, Faculty of Dentistry, Mansoura University, Egypt. \\ ${ }^{4}$ Department of Oral and Maxillofacial Surgery, Faculty of Medicine, Ghent University, Ghent, Belgium. \\ ${ }^{5}$ Faculty of Medicine, Hasselt University, Diepenbeek, Belgium.
}

\author{
Corresponding Author: \\ Jimoh Olubanwo Agbaje \\ 33 Kapucijnenvoer, 3000, Leuven \\ Belgium \\ Phone: +3216341963 \\ Fax: +32 16332437 \\ E-mail: joagbaje@gmail.com
}

\begin{abstract}
Objectives: The purpose of present study was to assess the surgical management of impacted third molar with proximity to the inferior alveolar nerve and complications associated with coronectomy in a series of patients undergoing third molar surgery. Material and Methods: The position of the mandibular canal in relation to the mandibular third molar region and mandibular foramen in the front part of the mandible (i.e., third molar in close proximity to the inferior alveolar nerve [IAN] or not) was identified on panoramic radiographs of patients scheduled for third molar extraction.

Results: Close proximity to the IAN was observed in 64 patients (35 females, 29 males) with an impacted mandibular third molar. Coronectomy was performed in these patients. The most common complication was tooth migration away from the mandibular canal $(n=14)$, followed by root exposure $(n=5)$. Re-operation to remove the root was performed in cases with periapical infection and root exposure.

Conclusions: The results indicate that coronectomy can be considered a reasonable and safe treatment alternative for patients who demonstrate elevated risk for injury to the inferior alveolar nerve with removal of the third molars. Coronectomy did not increase the incidence of damage to the inferior alveolar nerve and would be safer than complete extraction in situations in which the root of the mandibular third molar overlaps or is in close proximity to the mandibular canal.
\end{abstract}

Keywords: complications; impacted tooth; inferior alveolar nerve; third molar; oral surgery.

Accepted for publication: 23 June 2015

To cite this article:

Agbaje JO, Heijsters G, Salem AS, Van Slycke S, Schepers S, Politis C, Vrielinck L. Coronectomy of Deeply Impacted Lower Third Molar: Incidence of Outcomes and Complications after One Year Follow-Up

J Oral Maxillofac Res 2015;6(2):e1

URL: http://www.ejomr.org/JOMR/archives/2015/2/e1/v6n2e1.pdf

doi: 10.5037/jomr.2015.6201 


\section{INTRODUCTION}

Third molar extraction is the most common surgical procedure in the oral cavity and has been implicated in more than $50 \%$ of trigeminal nerve damage $[\underline{1}, \underline{2}]$. Complications occur intra-operatively or develop in the postoperative period; the complication rate related to third molar removal ranges from $4.6 \%$ to $30.9 \%$ $[\underline{3}, \underline{4}]$. The common reasons for extraction of the third molars in patients include multiple episodes of pericoronitis, pain, caries, orthodontic abnormalities, preparation for orthognathic surgery, and medical prophylaxis for cardiac surgery or endocarditis.

Surgical extraction of an impacted third molar is related to different degrees of extraction difficulty and complication risks, such as localised osteitis, postoperative infection, bleeding, periodontal defects, oroantral communication, fracture of the maxillary tuberosity or mandible, and peripheral trigeminal nerve injury $[\underline{3}, \underline{5-7}]$. Trigeminal nerve injury is a serious complication of surgical removal of the lower third molar, which results in a clinically relevant problem that deserves attention. The frequency of inferior alveolar nerve (IAN) damage after extraction of a third molar ranges from $0.26-8.4 \%$, whereas the lingual nerve (LN) sensory deficit ranges from 0.1 to $22 \%$ [2]. The risk of nerve injury is evaluated based on radiographic evidence of an intimate anatomic relationship between the root of the mandibular third molar (MTM) and the mandibular canal (MC) using either two-dimensional (panoramic) or threedimensional (cone beam computed tomography $[\mathrm{CBCT}]$, radiograph) [1]. The risk of IAN damage increases with increasing proximity of the root of the MTM to the MC.

Coronectomy is an alternative procedure to traditional extraction of MTM with fully developed roots in close contact with the MC. Evidence suggests that coronectomy is a good option for patients at risk of experiencing IAN injury [8], particularly for those with an increased risk of damage to the nerve.

Several studies have demonstrated that coronectomy significantly decreases the risk of iatrogenic injury to the IAN, with some studies also suggesting a lower complication rate [9-12].

The aim of the present study was to assess the complication of third molar in close proximity to inferior alveolar nerve treated with coronectomy in a series of patients seen for third molar surgery.

\section{MATERIAL AND METHODS}

This prospective study included all patients with deeply impacted lower third molar with close proximity to IAN undergoing third molar surgery in Ziekenhuis Oost-Limburg, Genk, Belgium between January 2012 and July 2013. This study complied with the principles laid down in the Declaration of Helsinki, and the study was approved by the Ethical Committees of Ziekenhuis Oost-Limburg. All subjects agreed and signed informed consent forms before being included in the study.

During the preoperative examination, panoramic radiographs were taken of all patients with the Orthophos XG plus scanner (Sirona Dental Systems, Bensheim, Germany) and the position of the MC from the MTM region to the mandibular foramen in the front part of the mandible determined. The position of the MC in relation to the root of the impacted MTM was assessed by separately recording the presence of the superior and inferior corticated borders of the canal on the panoramic radiograph of the right and left sides of all patients (Figure 1).

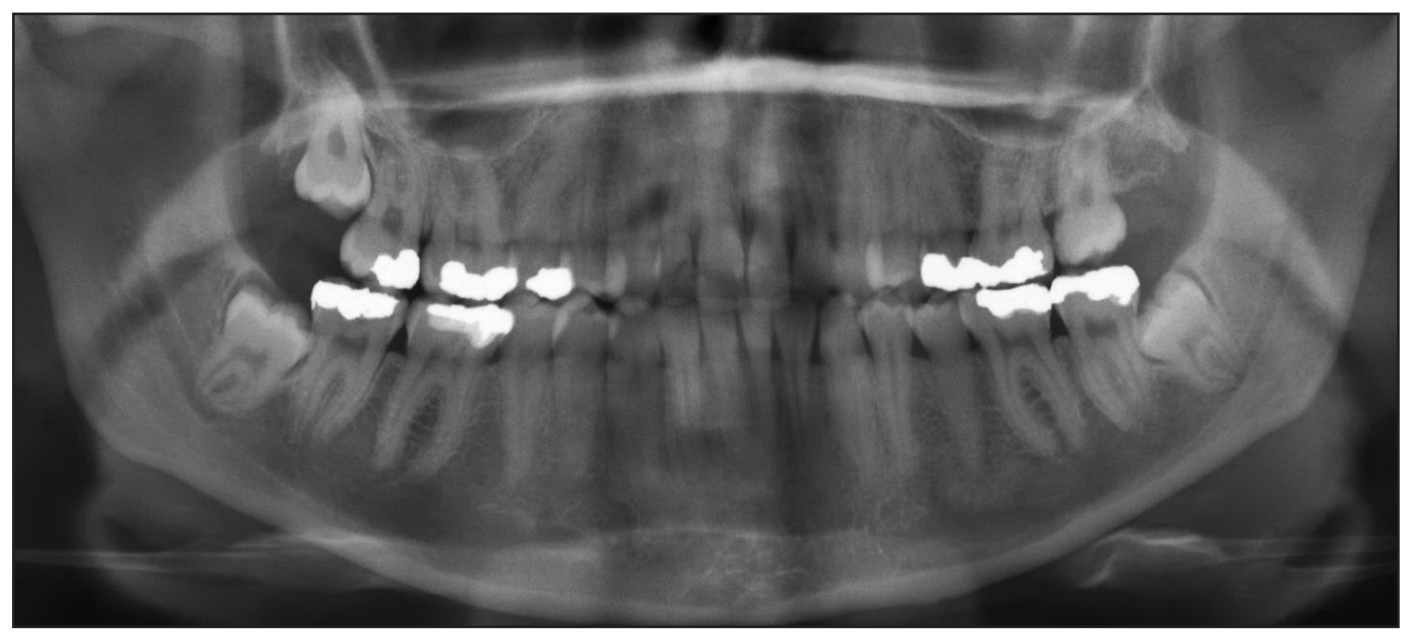

Figure 1. Panoramic radiograph showing bilateral impacted mandibular third molars and their relationship to the mandibular canal. 
The criteria for the inclusion of patients with impacted lower third molar in the study was based on the presence of one or more radiographic predictive signs on panoramic radiographs according to Rood criteria [13] these are: darkening of the root, interruption of the white line, diversion of the $\mathrm{MC}$, narrowing of the root, dark and bifid root, narrowing of the MC, and deflected root. All patients that showed positive predictive sign on panoramic radiograph undergo CBCT using the Galileos CBCT scanner (Sirona Dental Systems, Bensheim, Germany) for confirmation. The criteria for exclusion was the presence of pathological tissue changes around the impacted lower third molar such as cyst or tumour.

For the group in proximity to the IAN, an additional CBCT scan was performed to ascertain the relationship between the third molar, MC, and other surrounding structures in three dimensions (Figure 2). The reformatted cross sectional view was examined to see the relation of lower third molar and MC. The absence of cortication between the canal and molar roots was considered the criteria for close proximity to IAN [14].

Upon completion, panoramic views were automatically generated and presented using Galaxis software (Sirona Dental Systems, Bensheim, Germany). These panoramic radiographs were annotated with the position of the IAN and used during the operation to guide the surgeon.

The anatomy of the root of the MTM in relation to the $\mathrm{MC}$ was examined on axial and cross-sectional CBCT scans of cases with close proximity to the IAN. The angulation of the MTM was also assessed in addition to the relationship between the root of the MTM and the MC. All patients with an impacted MTM root in close proximity to the IAN were scheduled for coronectomy.

\section{Surgical technique}

All procedures were performed by the same surgeon (L.V.) using the same approach. The surgeon's experience included more than 10,000 third molar procedures. The surgical technique for coronectomy was as follows.

A full thickness mucoperiosteal incision was elevated with posterior buccal release. A conservative buccal trough was created using a round carbide bur on a surgical handpiece to allow access to the cementoenamel junction of the tooth. Care was exercised to maintain as much crestal bone height as possible by minimising the width of the buccal trough. After exposure was obtained, a Piezzo ultrasonic instrument with angulated head (Figure 3) was used

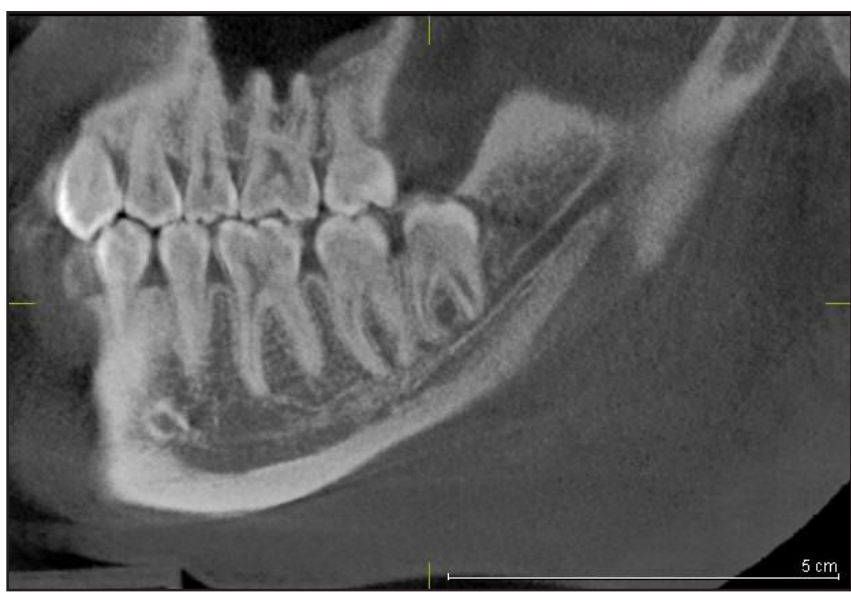

Figure 2. Multi-planer reformatted view of CBCT shows a close relationship between the impacted mandibular third molar roots and vital structures.

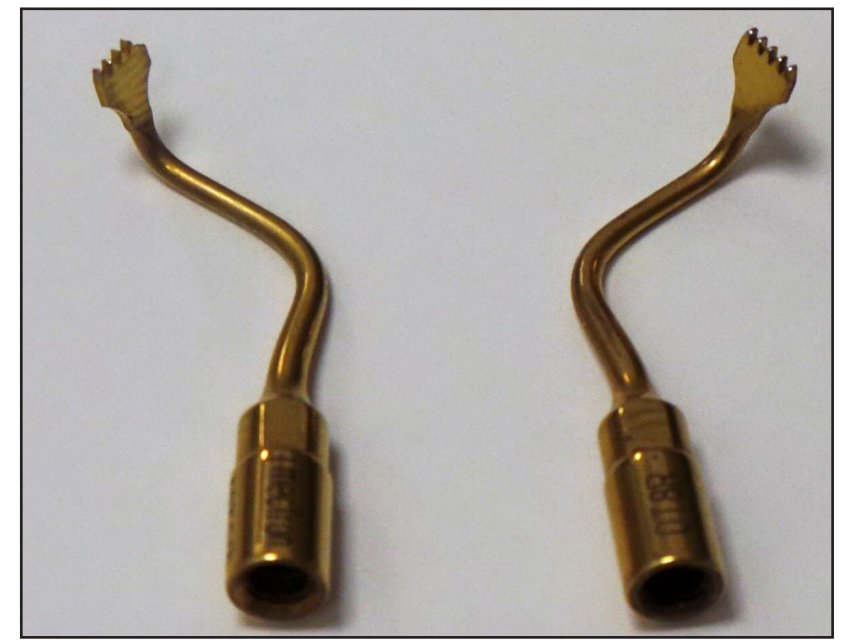

Figure 3. Bi-angulated Piezzo ultrasonic head used for coronal sectioning.

to make a horizontal cut through the tooth at the level of the cementoenamel junction. Sectioning of the crown was performed without perforation through the lingual bone plate. The crown was delicately fractured and separated from the residual roots of the tooth using a straight elevator or chisel. Effort was directed at minimising any mobilisation of the residual roots. Upon removal of the crown, any sharp fragments of the retained tooth structure were smoothed using a diamond round bur with simultaneous copious saline irrigation.

The remaining enamel was typically reduced approximately $3 \mathrm{~mm}$ below the buccal crest of the alveolar bone. Surgical wound was closed primarily.

\section{Post-operative assessment of complications}

Data from follow-up appointments for patients with deeply impacted MTM treated with the coronectomy technique were collected 12 months after the operation. 
The assessment and evaluation of all cases were done by the same surgeon who did the operation (L.V.). Each patient was reviewed, information on postoperative complications, such as periapical infection, delay healing, dry socket, pain, damage to adjacent structures, IAN injury, lingual nerve injury, root exposure, and migration of the root (Table 1), was collected. Pain considered complication was not the immediate post-operative pain but the pain that arise suddenly after the relief of initial post-operative pain and does not respond to analgesics. Nerve injury (lingual nerve and/or IAN) was evaluated by clinical assessment of patient symptoms and static light touch test. Root migration was evaluated by comparing the original root position to the cervical line of the adjacent lower second molar in immediate postoperative panoramic radiographs with that after 12 month.

\section{Statistical analysis}

Patient and operational outcomes were summarized by associated complications using descriptive statistics: number of observations (n). Counts and Percentages are used to summarize categorical variables.

\section{RESULTS}

Ninety six deeply impacted MTM with close proximity to IAN was found in 64 patients (36 females, 28 males). Coronectomy was performed on these 96 impacted MTMs.

The age distribution of the patients is presented in Figure 4. None of the patients treated with coronectomy had lingual nerve nor IAN impairment. Eighteen coronectomy sites in 12 subjects $(18.75 \%)$ presented with complications. The most common complication in our series was tooth migration away from the IAN $(\mathrm{n}=14)$, followed by root exposure $(n=5)$ then delay healing, periapical infection and pain $(n=4$ sites each). Some sites present with more than one complication. Re-operation to remove the root was performed in cases that presented with root exposure and periapical infection (Table 1).

Cases of dry socket and delayed healing were treated by wound debridement and irrigation, after which Alvogyl TM (Septodont; Saint-Maur-des-Fossés, France) paste dressing material was placed to control pain. These cases showed a good healing after treatment. Fractured of buccal mandibular plate was observed in two cases deeply impacted lower third molar, in these patients removal of the fractured plate, and smoothing of the surrounding bone was done with soft tissue closure.
Table 1. Complications of coronectomy and associated number of operating sites

\begin{tabular}{l|c}
\hline \multicolumn{1}{c|}{ Complication } & Number of teeth \\
\hline Migration away from Mandibular canal & 14 \\
\hline Root exposure & 5 \\
\hline Delay healing/dry socket & 4 \\
\hline Periapical infection & 4 \\
\hline Pain & 4 \\
\hline Buccal mandibular bone plate fracture & 2 \\
\hline Migration of the root towards the IAN & 0 \\
\hline Lingual nerve injury & 0 \\
\hline IAN injury & 0 \\
\hline Damage to adjacent structures & 0 \\
\hline
\end{tabular}

IAN $=$ inferior alveolar nerve.

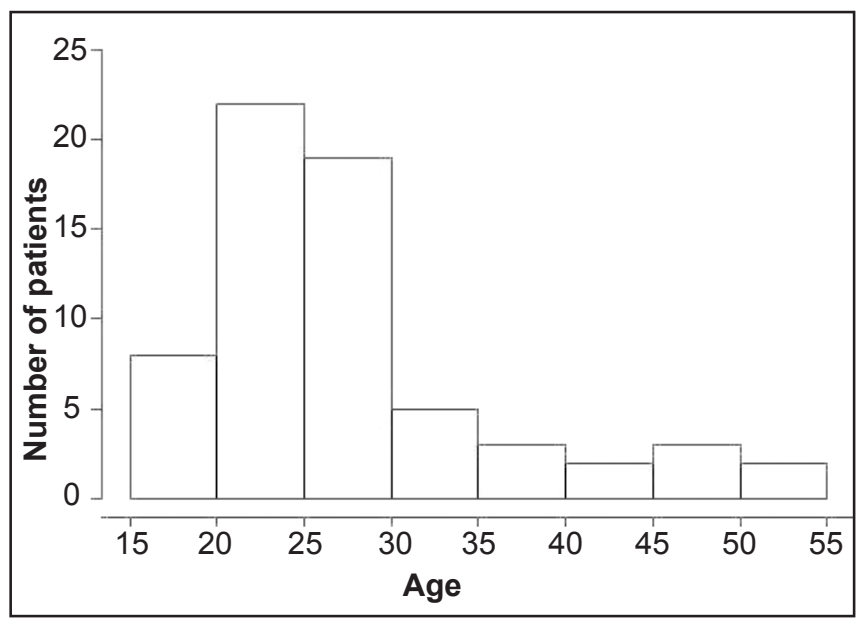

Figure 4. Age distribution of coronectomy patients.

\section{DISCUSSION}

Pre-operative assessment is an important step to prevent IAN injuries during surgical removal of impacted mandibular molars. Establishing the relationship between the IAN and the root in three dimensions using CBCT gives an indication of the level of risk to the nerve during surgical removal [15]. Many authors believe that coronectomy is a reasonable and safe treatment alternative for patients who demonstrate an elevated risk of IAN injury with the removal of third molars $[\underline{8-10}, \underline{16}]$.

The incidence of impacted MTM with close proximity to the IAN in this series was slightly higher in female with a male to female ratio of $1: 1.3$. The higher incidence of impacted mandibular molars in females has been attributed to late root development compared to males [17] and the fact that female jaws stop growing when third molars just begin to erupt, whereas in males, jaw growth continues beyond eruption of the third molar [18]. 
None of our patients who underwent coronectomy reported any incidence of IAN injury. The reduction in the incidence of injury to the IAN found in the study is in agreement with Rentol et al. [11], who compared the incidence of injury to the IAN as a result of coronectomy and removal of MTMs in a randomised controlled clinical trial; they concluded that coronectomy preserves the IAN without increasing the risk of dry socket or infection.

The surgical skill/experience of the operator has been indicated to be one of the main risk factors for developing permanent sensory dysfunction in the distribution of the IAN after coronectomy $[19,20]$. Jerjes et al. [19] indicated that patients treated by trainees have a higher prevalence of both IAN and LN paraesthesia, despite both groups of surgeons removing relatively equal numbers of teeth considered radiographically to be in close proximity to the IAN [19]. According to Umar et al. [12], permanent sensory disturbance in the IAN after third molar removal can be eliminated in high risk cases if operations are planned carefully (including CBCT) and performed by a skilled surgeon. The operating surgeon in our study has over 30 years of experience, which qualifies him to be considered as an experienced surgeon. The use of generated panoramic radiographs, as well as CBCT scans, to assess the relationship between the nerve and root of the third molar in three-dimensional view during the operation gives the surgeon a better understanding of the position of the IAN. The combination of an experienced surgeon and CBCT may be the reason for a lack of an increase in IAN damage in our study. However, an improved technique may also be a factor. The use of a Piezzo ultrasonic instrument makes coronal sectioning simpler and less traumatic compared to using a bur. In addition, the instrument allows less damage to the soft tissue and removes less bone. The angulated head of the Piezzo used to make the horizontal cut through the tooth at the level of the cementoenamel junction not only prevents perforation of the lingual plate, it also prevents damage to the surrounding tissues, which often occurs when a bur is used.

Root mobilisation has been described as the most common perioperative complication of coronectomy $[21,22]$, but we observed no cases of failed coronectomy owing to root mobilisation during the surgical procedure in our series, which can be the result of the method used for tooth sectioning. Mobilisation of the roots occurs when significant force is applied to fracture the crown of the tooth during the procedure; the use of a Piezzo instrument with angulated cutting head ensures clean sectioning of the coronal part of the tooth, requiring less force to detach the crown from the root.

Coronal migration of the roots has been reported as the most commonly reported long-term consequence of coronectomy $[11,21,22]$, which is confirmed by our finding that coronal migration accounts for $40 \%$ (14/35 sites) of the complications associated with coronectomy (Table 1). Coronal migration is often asymptomatic and is rarely a reason for re-operation [10].

\section{CONCLUSIONS}

The results indicate that coronectomy can be considered a reasonable and safe treatment alternative for patients who demonstrate elevated risk for injury to the inferior alveolar nerve with removal of the mandibular third molar. Coronectomy did not increase the incidence of damage to the inferior alveolar nerve and would be safer than complete extraction in situations in which the root of the mandibular third molar overlaps or is in close proximity to the mandibular canal.

\section{ACKNOWLEDGMENT AND DISCLOSURE STATEMENTS}

The authors report no conflicts of interest related to this study. Agbaje Jimoh Olubanwo of OMFSIMPATH Research Group, Department of Imaging and Pathology, Faculty of Medicine, Catholic University Leuven, Belgium is a postdoctoral researcher of the Fund for Scientific Research (FWOVlaanderen - 1277914N).

\section{REFERENCES}

1. Céspedes-Sánchez JM, Ayuso-Montero R, Marí-Roig A, Arranz-Obispo C, López-López J. The importance of a good evaluation in order to prevent oral nerve injuries: a review. Acta Odontol Scand. 2014 Apr;72(3):161-7. [Medline: 23822907] [doi: 10.3109/00016357.2013.812746]

2. Cheung LK, Leung YY, Chow LK, Wong MC, Chan EK, Fok YH. Incidence of neurosensory deficits and recovery after lower third molar surgery: a prospective clinical study of 4338 cases. Int J Oral Maxillofac Surg. 2010 Apr;39(4):320-6. [Medline: 20061121] [doi: 10.1016/j.ijom.2009.11.010] 
3. Bouloux GF, Steed MB, Perciaccante VJ. Complications of third molar surgery. Oral Maxillofac Surg Clin North Am. 2007 Feb;19(1):117-28, vii. Review. [Medline: 18088870] [doi: 10.1016/j.coms.2006.11.013]

4. Bui CH, Seldin EB, Dodson TB. Types, frequencies, and risk factors for complications after third molar extraction. J Oral Maxillofac Surg. 2003 Dec;61(12):1379-89. [Medline: 14663801] [doi: 10.1016/j.joms.2003.04.001]

5. Clauser B, Barone R, Briccoli L, Baleani A. Complications in surgical removal of mandibular third molars. Minerva Stomatol. 2009 Jul-Aug;58(7-8):359-66. Review. [Medline: 19633636]

6. Loescher AR, Smith KG, Robinson PP. Nerve damage and third molar removal. Dent Update. 2003 Sep;30(7):375-80, 382. Review. [Medline: 14558203]

7. Steed MB. The indications for third-molar extractions. J Am Dent Assoc. 2014 Jun;145(6):570-3. [Medline: 24878712] [doi: 10.14219/jada.2014.18]

8. Geisler S. Coronectomy is an effective strategy for treating impacted third molars in close proximity to the inferior alveolar nerve. J Am Dent Assoc. 2013 Oct;144(10):1172-3. [Medline: 24080934] [doi: 10.14219/jada.archive.2013.0036]

9. Long H, Zhou Y, Liao L, Pyakurel U, Wang Y, Lai W. Coronectomy vs. total removal for third molar extraction: a systematic review. J Dent Res. 2012 Jul;91(7):659-65. [Medline: 22622663] [doi: 10.1177/0022034512449346]

10. Monaco G, de Santis G, Gatto MR, Corinaldesi G, Marchetti C. Coronectomy: a surgical option for impacted third molars in close proximity to the inferior alveolar nerve. J Am Dent Assoc. 2012 Apr;143(4):363-9. [Medline: 22467696] [doi: 10.14219/jada.archive.2012.0178]

11. Renton T, Hankins M, Sproate C, McGurk M. A randomised controlled clinical trial to compare the incidence of injury to the inferior alveolar nerve as a result of coronectomy and removal of mandibular third molars. Br J Oral Maxillofac Surg. 2005 Feb;43(1):7-12. [Medline: 15620767] [doi: 10.1016/j.bjoms.2004.09.002]

12. Umar G, Obisesan $\mathrm{O}$, Bryant $\mathrm{C}$, Rood JP. Elimination of permanent injuries to the inferior alveolar nerve following surgical intervention of the "high risk" third molar. Br J Oral Maxillofac Surg. 2013 Jun;51(4):353-7. [Medline: 23010201] [doi: 10.1016/j.bjoms.2012.08.006]

13. Rood JP, Shehab BA. The radiological prediction of inferior alveolar nerve injury during third molar surgery. Br J Oral Maxillofac Surg. 1990 Feb;28(1):20-5. [Medline: 2322523] [doi: 10.1016/0266-4356(90)90005-6]

14. Maegawa H, Sano K, Kitagawa Y, Ogasawara T, Miyauchi K, Sekine J, Inokuchi T. Preoperative assessment of the relationship between the mandibular third molar and the mandibular canal by axial computed tomography with coronal and sagittal reconstruction. Oral Surg Oral Med Oral Pathol Oral Radiol Endod. 2003 Nov;96(5):639-46. [Medline: 14600702] [doi: 10.1016/S1079-2104(03)00356-1]

15. Sarikov R, Juodzbalys G. Inferior alveolar nerve injury after mandibular third molar extraction: a literature review. J Oral Maxillofac Res. 2014 Dec 29;5(4):e1. [URL: http://www.ejomr.org/JOMR/archives/2014/4/e1/v5n4e1ht.htm] [Medline: 25635208] [PMC free article: 4306319] [doi: 10.5037/jomr.2014.5401]

16. Stiefel KR, Baumgarten L. Coronectomy with the diagnostic use of CBCT to aid in the prevention of iatrogenic damage to the inferior alveolar nerve. Gen Dent. 2012 May-Jun;60(3):224-8. [Medline: 22623462]

17. Arany S, Iino M, Yoshioka N. Radiographic survey of third molar development in relation to chronological age among Japanese juveniles. J Forensic Sci. 2004 May;49(3):534-8. [Medline: 15171172] [doi: 10.1520/JFS2003372]

18. Quek SL, Tay CK, Tay KH, Toh SL, Lim KC. Pattern of third molar impaction in a Singapore Chinese population: a retrospective radiographic survey. Int J Oral Maxillofac Surg. 2003 Oct;32(5):548-52. [Medline: 14759117] [doi: 10.1016/S0901-5027(03)90413-9]

19. Jerjes W, Upile T, Shah P, Nhembe F, Gudka D, Kafas P, McCarthy E, Abbas S, Patel S, Hamdoon Z, Abiola J, Vourvachis M, Kalkani M, Al-Khawalde M, Leeson R, Banu B, Rob J, El-Maaytah M, Hopper C. Risk factors associated with injury to the inferior alveolar and lingual nerves following third molar surgery-revisited. Oral Surg Oral Med Oral Pathol Oral Radiol Endod. 2010 Mar;109(3):335-45. [Medline: 20097103] [doi: 10.1016/j.tripleo.2009.10.010]

20. Bataineh AB. Sensory nerve impairment following mandibular third molar surgery. J Oral Maxillofac Surg. 2001 Sep;59(9):1012-7; discussion 1017. Review. [Medline: 11526568] [doi: 10.1053/joms.2001.25827]

21. Gady J, Fletcher MC. Coronectomy: indications, outcomes, and description of technique. Atlas Oral Maxillofac Surg Clin North Am. 2013 Sep;21(2):221-6. [Medline: 23981497] [doi: 10.1016/j.cxom.2013.05.008]

22. Patel V, Gleeson CF, Kwok J, Sproat C. Coronectomy practice. Paper 2: complications and long term management. Br J Oral Maxillofac Surg. 2013 Jun;51(4):347-52. [Medline: 22794945] [doi: 10.1016/j.bjoms.2012.06.008]

\section{To cite this article:}

Agbaje JO, Heijsters G, Salem AS, Van Slycke S, Schepers S, Politis C, Vrielinck L. Coronectomy of Deeply Impacted Lower Third Molar: Incidence of Outcomes and Complications after One Year Follow-Up.

J Oral Maxillofac Res 2015;6(2):e1

URL: http://www.ejomr.org/JOMR/archives/2015/2/e1/v6n2e1.pdf

doi: $10.5037 /$ jomr.2015.6201 
Copyright (C) Agbaje JO, Heijsters G, Salem AS, Van Slycke S, Schepers S, Politis C, Vrielinck L. Published in the JOURNAL OF ORAL \& MAXILLOFACIAL RESEARCH (http://www.ejomr.org), 30 June 2015.

This is an open-access article, first published in the JOURNAL OF ORAL \& MAXILLOFACIAL RESEARCH, distributed under the terms of the Creative Commons Attribution-Noncommercial-No Derivative Works 3.0 Unported License, which permits unrestricted non-commercial use, distribution, and reproduction in any medium, provided the original work and is properly cited. The copyright, license information and link to the original publication on (http://www.ejomr.org) must be included. 